\title{
TECNOLOGIAS DE INFORMAÇÃO E COMUNICAÇÃO COMO ALTERNATIVAS PARA O ENSINO DE GEOGRAFIA: MEMÓRIAS E RELATOS DOCENTES
}

\author{
INFORMATION AND COMMUNICATION TECHNOLOGIES AS ALTERNATIVES FOR TEACHING \\ GEOGRAPHY: MEMORIES AND TEACHING REPORTS
}

\author{
http://orcid.org/0000-0002-5521-2049 Thiago Barcelos Pereira ${ }^{\text {A }}$ \\ (D) http://orcid.org/0000-0002-0846-0621Vilmar José Borges ${ }^{\text {B }}$ \\ ${ }^{\text {A }}$ Secretaria Estado da Educação (SEDU-ES), Cariacica, ES, Brasil \\ ${ }^{\text {B }}$ Universidade Federal do Espírito Santo (UFES), Vitória, ES, Brasil \\ Recebido em: 18 jun. 2020 | Aceito em: 17 mar. 2021 \\ Correspondência: Thiago Pereira (barcelosthc@gmail.com)
}

\begin{abstract}
Resumo
As tecnologias de informação e comunicação (TICs) fazem parte do cotidiano dos jovens estudantes da Educação Básica. Nesse sentido, o presente artigo objetiva socializar reflexões acerca de saberes e fazeres de professores de Geografia na busca pela incorporação das TICs como alternativa para o ensino. Para tanto, apoiados na história oral, buscou-se narrativas de professores atuantes na Educação Básica nas redes pública municipal e estadual de ensino no município de Cariacica-ES, dando visibilidade aos saberes e fazeres de profissionais na incorporação das TICs como alternativa de ensino. A pesquisa revela que para além das dificuldades impostas pela realidade social e da escola pública, as TICs apresentam-se como potentes alternativas de ensino e de inclusão social.
\end{abstract}

Palavras-chave: TICs; Narrativas; Ensino de Geografia; Prática docente.

\begin{abstract}
Information and communication technologies (TICs) are part of the daily lives of young students of Basic Education. In this sense, this article aims to socialize reflections about the knowledge and practice of teachers of Geography in the search for the incorporation of TICs as an alternative for teaching. To do so, supported by oral history, narratives of teachers working in Basic Education in the public municipal and state schools in the municipality of CariacicaES were sought, giving visibility to the knowledge and practices of professionals in the incorporation of TICs as a teaching alternative. The research reveals that in addition to the difficulties imposed by the social reality and the public school, TICs present themselves as powerful alternatives for teaching and social inclusion.
\end{abstract}

Keywords: TICs; Narratives; Geography teaching; Teaching practice.

\section{Introdução}

Atualmente vivemos um momento de grande avanço tecnológico nos mais diversos setores da sociedade, tais como a indústria, a saúde, a agrícola, os sistemas de informação e, também, em decorrência e por consequência, na educação. 
No Brasil, especificamente, no que tange à educação básica, já é possível encontrar em algumas escolas lousa digital, data shows, computadores com diversas funções capazes de colaborar no processo de ensino aprendizagem, servindo de fonte para novas práticas de ensino.

Diante de tantas transformações propiciadas pelos avanços tecnológicos, tanto a escola quanto o professor se deparam com o emergente desafio que se configura na necessidade de se adaptar para conviver com um aluno que vai deixando de viver em uma sociedade analógica e partindo para uma sociedade cada vez mais digital. Nesse contexto, destacamos as Tecnologias da Informação e Comunicação (TIC's), que são resultantes da união entre informática e telecomunicação e que passaram a se inserir sistematicamente nos centros metropolitanos, disseminando-se gradativamente entre as diferentes classes sociais, influenciando, por consequência, as relações no espaço escolar.

Depreende-se, pois, que as TIC's vêm ganhando cada vez mais importância, uma vez que o seu desenvolvimento representa e impacta em transformações nos mais variados aspectos da sociedade. Esse desenvolvimento e presença das TIC's vêm permeando, de uma maneira geral, todos os espaços da sociedade e, como tal, exigindo que os envolvidos no espaço educacional, entre eles os professores, adotem uma nova postura em seus fazeres e em suas práticas diárias, principalmente no que tange às relações de ensino- aprendizagem com os alunos.

Especificamente com relação à Geografia e seu ensino, ao se proporem estudar o espaço e as relações de espacialidades, com vistas a contribuir com a formação da cidadania discente, esse desafio se faz ainda mais urgente e latente. Conforme bem salienta Almeida (2000), ensino e a aprendizagem em Geografia transformaram-se com o uso das TIC's. Segundo a autora, por meio de suportes (mídias) e de meios de comunicação (como jornal, televisão, rádio e internet), essas tecnologias possibilitam o acesso e a veiculação de informações de todas as formas de articulação comunicativa em todo mundo, influenciando cada vez mais na maneira que os professores de Geografia planejam e desenvolvem suas aulas.

No entanto, essas novidades digitais colocam aos professores um grande dilema, qual seja, por um lado a certeza da necessidade de incorporar essas novas tecnologias de ensino ao seu dia-a-dia, e, por outro lado, a insegurança gerada pela falta de preparo ao utilizá-las. Isso acentua e evidencia a importância e a necessidade da busca por alternativas que propiciem a esses docentes uma atualização no uso dessas ferramentas, no intuito de tornar suas aulas mais atrativas e próximas da realidade na qual vivem seus alunos. É nesse cenário que situamos nossa pesquisa, que visa em última análise, "garimpar" e socializar narrativas de experiências e 
vivências docentes, pautadas na utilização das TICs, no ensino de Geografia na Educação Básica, em escolas da rede pública.

Assim, objetivamos socializar análises e reflexões propiciadas por narrativas de docentes acerca de experiências de ensino de Geografia na Educação Básica, implementadas no cotidiano de escolas públicas no município de Cariacica-ES, utilizando como recursos metodológicos as tecnologias da informação e comunicação (TICs).

Salienta-se, de imediato, conforme bem explicitam Borges e Bitte (2017), a importância de nos voltarmos para a cotidianidade das práticas pedagógicas, tomando como campo de análise e de reflexões os espaços de vivência docente, seus saberes e seus fazeres. Segundo os referidos autores, o professor, no exercício de sua função docente "modela, adequa e transforma o saber sistematizado, tornando-o acessível ao aluno" (p.35).

...os professores são tomados como os produtores de seus próprios saberes, quando, no exercício de sua função docente, desenvolvem truques, esquemas e estratagemas que lhes possibilitem superar as mais diversas situações, que, embora corriqueiras, são dinâmicas. Essas técnicas, truques e estratagemas desenvolvidos pelo docente na 'solidão' de si com suas 'repletas' salas de aulas são saberes que lhe são particulares e, se não socializados, permanecem em segredo. (BORGES; BITTE, 2018, p. 42)

Assim, sem a pretensão de esgotar as possibilidades de utilização e adequação das TICs como auxiliares ao ensino de Geografia e de suas contribuições para o processo de ensino aprendizagem, buscamos mapear saberes e práticas de ensino de Geografia que envolve as TIC's, no intuito de subsidiar outros saberes e, também novos fazeres, visto que, não obstante os limites impostos pela carência de infraestrutura adequada, diversos docentes já se apropriaram de tal alternativa de ensino. Compartilhar esses saberes por intermédio de narrativas pode favorecer uma maior aproximação com algumas realidades, mediante a leitura diversificada do espaço geográfico, e de temas de grande interesse e relevância para os alunos e comunidade escolar.

Nessa direção, o caminho metodológico eleito para a coleta de narrativas docentes se pautou nos pressupostos da História Oral.

Segundo Bom Meihy,

História oral é um recurso moderno usado para a elaboração de documentos, arquivamento e estudos referentes à vida social de pessoas. Ela é sempre uma história do tempo presente e também conhecida por história viva. (...) a história oral se apresenta como forma de captação de experiências de pessoas dispostas a falar sobre aspectos de sua vida mantendo um compromisso com o contexto social. (BOM MEIHY,1996, p. 13) 
Conforme salienta o referido autor, a história oral apresenta-se como um eficiente recurso de pesquisa, ao possibilitar a elaboração de registros e documentar experiências, saberes e práticas de pessoas, a respeito de suas vivências e concepções. Essa concepção coaduna com a advertência de Delgado (2006), no sentido de que “... o passado espelhado no presente reproduz através de narrativas, a dinâmica da vida pessoal em conexão com processos coletivos" (p.15). Portanto, essa metodologia se torna uma eficaz ferramenta para desvendar práticas muitas vezes esquecidas do/no dia a dia dos docentes, ou seja, como alternativa para captar experiências e registrar vivências de pessoas dispostas a falar sobre aspectos de sua vida, mantendo um compromisso com o contexto social.

Nessa direção, e apoiados em tais pressupostos, buscamos ouvir e dar vozes a professores de Geografia que vêm utilizando as novas tecnologias de informação e comunicação, como alternativas de ensino em sala de aula, no intuito de desvelar pistas e sinais que possam fornecer contribuições, para conhecermos o que já tem sido feito e posto em prática em relação a essa temática, principalmente no espaço das escolas públicas, já que é de conhecimento de todos as variadas dificuldades que essa realidade impõe.

Nessa perspectiva, ao utilizarmos as narrativas docentes como fio condutor desse artigo, partimos do pressuposto, como bem assevera Benjamin (1985), que elas podem nos levar a pensar, a refletir junto com o narrador, e nos fazer recontar aquilo que aprendemos, podendo assim ensinar e aprender com as experiências e vivências dos nossos docentes colaboradores, propiciando novas reflexões sobre as práticas exercidas nas salas de aula e sua eficácia para o alcance e abrangência da aprendizagem dos alunos.

De acordo com Kenski (1997), “o professor enquanto agente de memória informal, educativa, na sociedade digital é capaz de realizar interações e intercâmbios entre linguagens, espaços, tempos e conhecimentos (pontes sociais, temporais, tecnológicas) diferenciados” ( $\mathrm{p}$. 27), conseguindo exercer um papel fundamental na mediação entre o que é novo, antigo e eficaz, quando está preparado para enfrentar os novos desafios e inovações no espaço social e educacional.

Mediante o exposto, na busca por narrativas docentes que desvelem práticas relacionadas à produção, reprodução e mobilização de diferentes saberes gestados na utilização das Tecnologias da Informação e Comunicação como alternativa ao ensino de Geografia, encontramos respaldo e acolhida em dois professores, que generosamente se dispuseram a compartilhar conosco seus saberes e seus fazeres. Assim, foram nossos companheiros de diálogo os professores Fledson Silva Faria, licenciado em Geografia pela Universidade Federal do Espírito Santo; e Silas Ribeiro dos Santos, licenciado em Geografia pela Universidade de 
Uberaba-MG, que concordaram com sua identificação, não sendo, portanto, necessário recorrermos aos critérios de invisibilidade.

Nossos sujeitos colaboradores são professores de Geografia, atuantes nos anos finais do Ensino Fundamental, em escolas da rede pública de ensino no município de Cariacica-ES e vêm, há algum tempo, utilizando das Tecnologias da Informação e Comunicação como recursos metodológicos para o ensino de Geografia. Ao serem contactados, os mesmos concordaram voluntariamente com a participação da pesquisa. Assim, foram agendadas a realização das respectivas entrevistas, que ocorreram em datas, locais e horários definidos pelos mesmos e duraram, em média, cerca de trinta minutos cada, onde nossos colaboradores puderam recontar sua trajetória no ambiente escolar, seus êxitos e dificuldades, além das novas possibilidades e potencialidades fornecidas pelas novas tecnologias e os impactos percebidos na aprendizagem dos alunos.

Vale ressaltar que, conforme mencionado anteriormente, nossos colaboradores atuam em escolas da rede pública do ensino fundamental, no município de Cariacica-ES, situadas em áreas periféricas, conforme narram

...eu agradeço a oportunidade de participar de suas reflexões. Tenho, ao todo, quinze anos de atuação docente na rede estadual do Espírito Santo, como professor de Geografia. Na Escola Estadual de Ensino Fundamental Manoel Paschoal de Oliveira, que fica no bairro Nova Canaã, em Cariacica, eu comecei a atuar em fevereiro desse ano. É a primeira vez que eu trabalho nessa escola. Ela fica próxima a minha casa, conheço bem a realidade da escola, mas é a primeira vez que eu estou trabalhando. (FARIA, 2019)

Eu me formei em 2013 na Universidade de Uberaba em Minas Gerais. Na docência, estou atuando desde 2012, visto que comecei a dar aula, quando ainda cursava o quarto período. De lá para cá não parei de atuar na área. Atualmente, leciono na rede estadual nas Escolas Ary Parreiras, Augusto Luciano e Zaíra Manhães de Andrade, todas no município de Cariacica. (SANTOS, 2019)

Apesar de possuírem experiências vivenciadas em diversos bairros e realidades da Região Metropolitana de Vitória-ES ${ }^{i}$, ambos estão atuando em escolas públicas, situadas em regiões periféricas de um município carente de condições de infraestrutura adequadas para o ensino público de melhor qualidade. Não obstante, nossos colaboradores relatam esforços no sentido de utilizarem das tecnologias da informação e comunicação como recurso alternativo para o ensino de Geografia.

\section{Reflexões sobre a tecnologia no ensino de Geografia}

De acordo com a Base Nacional Curricular Comum (BNCC), a Geografia, junto a outras disciplinas da Ciência Humana na educação básica, deve enfatizar as aprendizagens dos 
estudantes relativas ao desafio de dialogar com o outro e com as novas tecnologias. Considerando que as novas tecnologias exercem influência, às vezes negativa, outras vezes positiva, no conjunto das relações sociais, é necessário assegurar aos estudantes a análise e o uso consciente e crítico dessas tecnologias. Para tanto, torna-se de suma importância instrumentalizar e propiciar condições de equidade que possibilite ao estudante a participação social efetiva. Dessa forma, o ensino da Geografia não deve ficar alheio à forte presença cotidiana e, consequentemente, às potencialidades que o uso das TICs e suas ferramentas digitais fornecem como auxiliares à efetivação do processo ensino-aprendizagem.

De acordo com a Base Nacional Curricular Comum (BNCC),

Essa constante transformação ocasionada pelas tecnologias, bem como sua repercussão na forma como as pessoas se comunicam, impacta diretamente no funcionamento da sociedade e, portanto, no mundo do trabalho. A dinamicidade e a fluidez das relações sociais - seja em nível interpessoal, seja em nível planetário - têm impactos na formação das novas gerações. É preciso garantir aos jovens aprendizagens para atuar em uma sociedade em constante mudança. (BRASIL, 2017, p. 473)

O uso das Tecnologias da Informação e Comunicação (TIC's) faz parte do cotidiano da geração atual, que se depara constantemente com o acesso e um volume de informações bastante diferentes de décadas atrás. Portanto, cabe ao professor auxiliar seus alunos, instrumentalizando-os a filtrá-las, colaborando no recebimento e detalhamento dessas informações. Essa percepção fica evidenciada na narrativa de nosso colaborador:

Na Geografia falamos que vivemos em constante transformação, e que temos que nos adaptar as tecnologias. Hoje em dia trabalhamos com uma geração que é totalmente diferente, da geração de estudantes da década de 90 e 80 . A geração de hoje está mais antenada, e com muitas informações. (SANTOS, 2019)

Os historiadores estadunidenses Nile Howe e William Strauss (1992), tornaram-se referências ao aplicarem, na prática, os conceitos de geração que foram surgindo na sociologia contemporânea. Segundo os mesmos, a configuração de uma geração não se limita ao compartilhamento da data de nascimento e sim, de uma série de circunstâncias históricas que marcam um antes e um depois na vida coletiva. Dessa forma, além de Howe e Strauss, vários autores também contribuíram na conceituação das diferentes gerações, que foram denominadas de X, Y e Z.

De acordo com Serrano (2011), a Geração X pode ser assim classificada: "têm sua data de nascimento localizada, aproximadamente, entre os anos de 1960 e 1980. A Geração X é formada pelos filhos da Geração Baby Boomers ${ }^{i i}$, formada logo após a Segunda Guerra Mundial 
e pelos pais da Geração Y” (p. 15). Essa geração caracteriza-se pela individualidade sem a perda da convivência em grupo, pela busca da liberdade e ruptura com as gerações anteriores.

Os indivíduos da Geração Y são popularmente conhecidos como Millennials, ou ainda, Geração do Milênio ou da Internet. Esse conceito sociológico denomina, via de regra, aqueles que nasceram no início dos anos 1980 até meados dos anos 1990. Foi a primeira geração que nasceu em meio ao desenvolvimento tecnológico e, portanto, tiveram acesso às tecnologias, mesmo que de forma incipiente.

Já a geração Z, por sua vez, abrange os sujeitos nascidos entre meados dos anos 1990 até 2010, marcados por possuírem uma ultraconexão tecnológica. Portanto, acreditam que a pluralidade de culturas e opiniões é fundamental para a sociedade, são, também ser conhecidos também como "nativos digitais".

Para Palfrey e Gasseros (2011), os nativos digitais aprendem como usar um novo software rapidamente e estão criando mundos paralelos. Os referidos autores esclarecem, ainda, que a formação da identidade entre os "nativos digitais" é diferente da formação da identidade entre as gerações pré-digitais, no sentido de que há mais experimentação e reinvenção das identidades, bem como que os modos de expressar essa identidade parecem, muitas vezes, aos pais e professores, mais estranhos do que realmente são.

Nesse cenário, percebe-se que estamos envoltos pelas tecnologias e pelas transformações que elas impactam nos mais diversos espaços e realidades, e portanto, é latente a necessidade de refletimos sobre um ambiente educacional que prepare e forme cidadãos capazes de lidar com esse avanço tecnológico, sendo sujeitos ativos e críticos, conhecedores das consequências de sua atuação, conforme bem pondera Moran:

Aprendemos mais quando estabelecemos pontes entre a reflexão e a ação, entre a experiência e a conceituação, entre a teoria e a prática; quando ambas se alimentam mutuamente. Aprendemos quando equilibramos e integramos o sensorial, o racional, o emocional, o ético, o pessoal e o social. Aprendemos pelo prazer, porque gostamos de um assunto, de uma mídia, de uma pessoa. O jogo, o ambiente agradável, o estímulo positivo podem facilitar a aprendizagem. Aprendemos mais, quando conseguimos juntar todos os fatores: temos interesse, motivação clara; desenvolvemos hábitos que facilitamos processo de aprendizagem; e sentimos prazer no que estudamos e na forma de fazê-lo. (MORAN, 2006, p.22)

Diante de tal realidade, a escola e os professores não podem ficar à mercê do que está se desenvolvendo no planeta e em grande parte das sociedades que o habitam. Trabalhar a realidade próxima do aluno e do professor é de fundamental importância, conforme bem salientam Sampaio e Leite (2008), ao discutirem a formação docente, 
Se concordarmos que o aluno deve ser sujeito do conhecimento, as iniciativas de formação de professores devem também ver este profissional como sujeito do conhecimento e trabalhar com ele nesta perspectiva. Se o objetivo é conscientizar os alunos e torná-los participativos, a educação dos professores não pode visar apenas a internalização do saber [...] mas deve incluir também a sua problematização, a sua conscientização [...] percebendo-o como sujeito do conhecimento. (SAMPAIO; LEITE, 2008, p. 70)

Não obstante sua relevância, bem como suas potencialidades, há que se considerar, também, a advertência de Pessoa (2011), ao afirmar que as tecnologias, uma vez utilizadas como instrumento para auxiliar esse desenvolvimento, de nada irão servir se o professor não estiver preparado para usá-la com competência.

Nesse contexto os profissionais de educação necessitam estar em constante busca de atualização e novas formações. O educador atualizado e em formação ininterrupta se torna um facilitador e não apenas um transmissor de informações. Além disso, a formação contínua ajuda o professor a se tornar cada vez mais capaz de se adaptar às rápidas e diversas mudanças do contexto educacional, contornando as dificuldades encontradas no dia a dia da sala de aula. E, visando contribuir com esse processo de formação contínua do professor, um caminho alternativo, possível e necessário, passa pela coleta e socialização de saberes e de fazeres de outros professores, acerca das vivências e experiências de ensino implementadas no cotidiano de suas respectivas salas de aula.

As TIC's, quando bem utilizadas pelo professor, podem se tornar ferramentas educacionais úteis a essa mudança de perfil de sociedade, podendo colaborar para que o aluno tenha um maior interesse em aprender e uma maior facilidade na assimilação dos conteúdos, tendo também, e consequentemente, uma melhor formação como cidadão.

No entanto, tendo em vista que, via de regra, os professores e seus alunos são de gerações diferentes, a utilização das TIC's no ensino é um verdadeiro desafio que se apresenta para o professor no desenvolvimento de sua aula. Consideram-se, ainda, obstáculos decorrentes das relações de interação da disciplina com a escola, e seus reais objetivos que perpassa por uma valorização do trabalho coletivo, interdisciplinar e que consiga abranger as necessidades e anseios dos alunos, visto que, conforme adverte Alarcão:

O professor não pode agir isoladamente na sua escola. É neste local, o seu local de trabalho, que ele, com os outros, seus colegas, constrói a profissionalidade docente. Mas se a vida dos professores tem o seu contexto próprio, a escola esta tem de ser organizada de modo a criar condições de refletividade individuais e coletivas. Vou ainda mais longe. A escola tem de se pensar a si própria, na sua missão e no modo como se organiza para cumprila. Tem, também ela, de ser reflexiva. (ALARCÃO, 2004, p. 44) 
A proposta de utilização das TICs como alternativa ao ensino de Geografia deve considerar, portanto, que a necessária busca por uma formação continuada constante do professor, permitirá uma maior variação de técnicas e práticas pedagógicas, colaborando cada vez mais em sua rotina escolar e possibilitando uma maior qualidade nas aulas de Geografia.

No entanto, há que se considerar que a busca pela formação continuada deve permear todo o processo identitário docente, conforme bem salientam Borges e Bitte,

O processo identitário docente é uma construção permanente, permeada pelos diversos saberes com os quais o professor se relaciona no seu cotidiano. A atividade docente e, por conseguinte, a construção da identidade docente exige uma formação contínua e esse processo de formação não pode ser considerado e efetivado apenas por cursos formais, mas deve ser visto em toda a sua complexidade. (2018, p. 34)

A profissão docente é uma construção cotidiana e o docente não deve deixar de estudar. Essa constatação fica, também, bastante evidenciada na própria política educacional brasileira, expressa na Lei de Diretrizes e Bases da Educação Nacional - LDB, nº 9.394/96, como também o Plano Nacional de Educação, que asseveram que o professor, no exercício de sua função, deve estar constantemente buscando melhorar suas práticas, evitando se tornar ultrapassado em sua atividade.

Nessa direção, Prado (2008) afirma que:

É preciso investir na formação do professor, propiciando o desenvolvimento de sua capacidade crítica, reflexiva e criativa. Dessa forma, não basta o professor aprender a operacionalizar o computador, isto é, saber ligar e colocar um software para o aluno usar. O professor precisa vivenciar e compreender as implicações educacionais envolvidas nas diferentes formas de utilizar o computador, a fim de poder propiciar um ambiente de aprendizagem criativo e reflexivo para o aluno. (PRADO, 2008, p. 4)

Não obstante tais constatações, inúmeras dificuldades são impostas para aqueles profissionais que desejam e buscam por esta tão decantada e necessária atualização. Apenas sua disponibilidade de querer melhorar a sua prática, em muitos casos, não é o suficiente para que isso ocorra. Questões como infraestrutura, e questões burocráticas impedem os profissionais de conhecer, dominar e utilizar de forma reflexiva as novas ferramentas tecnológicas, sendo imprescindível o oferecimento de boas condições aos professores, diante disso, Morais afirma que:

Não basta apenas levar os modernos equipamentos para a escola, como querem algumas propostas oficiais. Não é suficiente adquirir televisões, videocassetes, computadores, sem que haja uma mudança básica na postura do educador, pois isso reduzirá as tecnologias a simples meios de informação (MORAIS, 2000, p.38). 
Assim, sem a pretensão de esgotar as discussões e possibilidades, nos propomos socializar narrativas de docentes, acerca de seus saberes e seus fazeres, que desvelem sinais e pistas que possam subsidiar outros saberes e outros fazeres, rumo à busca pela melhoria da qualidade do ensino de Geografia.

\section{Relatos e experiências docentes}

De acordo com Nogueira (2007), é necessário desenvolver análise e reflexões sobre os processos de formação em serviço dos professores, considerando-os como sujeitos edificadores e elaboradores de sentido ao longo do processo de sua própria formação. Segundo o autor, o professor, apesar de ter seus próprios modos de ensinar, necessita constantemente estar atualizando sua formação e práticas, diante das mudanças que surgem ao longo dos anos.

É nesse cenário que se inserem nossas reflexões no campo da pesquisa educacional, especialmente no que diz respeito ao campo do ensino de Geografia, visando instigar e contribuir com novas reflexões que possam acrescentar ao tema algumas alternativas, elucidando, conceitualmente, a questão da relação entre o ensino da Geografia, as novidades digitais e as práticas adotadas pelos docentes explícitas em suas narrativas.

Acredita-se, conforme Carvalho e Vlach (2007), que os raciocínios geográficos podem e devem contribuir efetivamente para formar cidadãos plenos e ativos, na perspectiva de contribuir com a compreensão de problemas do mundo atual, muitos dos quais estão ligados à convivência social no seu sentido mais amplo.

É praticamente consenso na comunidade escolar que as novas tecnologias fazem parte do cotidiano, tanto do professor quanto de seus alunos. Também é consenso que as tecnologias possibilitam uma gama de potencialidades e, portanto, o docente não pode abstrair de sua prática, como alternativa para o ensino. Segundo Andrade et al. (2016, p. 608), utilizar as Tecnologias de Informação e Comunicação (TICs), para ajudar o aluno a compreender sua realidade é um grande passo para que o mesmo possa entender o espaço geográfico de forma criativa e prazerosa. Essa percepção tem sido compartilhada e implementada pelo nosso colaborador, conforme sua narrativa:

Hoje não tem como você trabalhar com adolescentes na educação sem usar a tecnologia. Se você proibi-los de usar, eles irão usar celulares, Smartphones que eles têm. E a maioria tem. Mesmo em bairros mais periféricos, mais carentes... Se você proibir, eles serão usados de qualquer forma. Então, vejo como importante usar como ferramenta didática, visto que é melhor você controlar o uso, do que deixar eles usarem de qualquer forma. É importante e necessário, uma vez que a geração de hoje não vive sem tecnologia, logo, a gente tem que usar como ferramenta. (FARIA, 2019) 
Tomando como ponto de partida o relato do professor, percebe-se que no contexto atual, onde existe uma grande variedade de linguagens, onde se movimentam diversas informações, que são potencializadas pelas novas tecnologias, se torna imprescindível o papel do professor, na busca por apropriar-se de tais recursos em favor do seu ensino, de maneira geral. Especificamente, no que se refere ao ensino de Geografia, percebemos que se "abre" uma janela de oportunidades para serem exploradas pelos docentes, conforme bem explicita Farias,

Vou pegar como exemplo o que eu falei sobre o Minigeocraft (GAME) que foi uma experiência de ensino bastante exitosa. O planejamento começou com a ajuda dos alunos. Meu filho, que era aluno da escola e, também, meu aluno, juntamente com outro coleguinha dele, que gostavam do jogo, me propuseram trabalhar com esse jogo. Para tanto, me deram, inclusive dicas sobre conteúdos de Geografia que poderiam ser trabalhadas no mesmo. Eu não conhecia o jogo, e o que eu conhecia tinha até um pouco de aversão, porque eu via meu filho jogando em casa e não enxergava nada de positivo. Então ele, juntamente com o colega me convenceram a bolar a eletiva. Nas eletivas, que eram aulas alternativas, a gente trabalhava coordenadas geográfica, latitude, longitude e biomas dentro da Geografia. Eu fiz uma parceria com o professor de matemática, que já conhecia o jogo e tinha uma afinidade muito grande com o uso de Tic's, visto que usa as Tic's em sala de aula com muita frequência. Com o jogo pode trabalhar plano cartesiano, $\mathrm{X}$ e Y... A experiência com o jogo foi muito legal. Tivemos problemas de alguns alunos pararem e irem migrando para outro jogo, mas a gente conseguiu desenvolver os conteúdos. Então eu posso dizer, ao comparar o fato de já ter a experiência de ter trabalhado o mesmo conteúdo sem Tic's, sem dúvida alguma, que o aprendizado foi muito maior. (FARIA, 2019)

A narrativa acima revela que ao planejar o trabalho de temas da Geografia utilizando as TICs, professor deve prever e esperar que o aluno tenha algum conhecimento quanto ao do uso dos recursos tecnológicos. Assim, o professor deverá saber como relacionar os conceitos geográficos abordados durante as aulas, com os saberes dos alunos acerca da tecnologia utilizada como recurso de ensino. Isso, dentre outros fatores, dá ao aluno uma posição de sujeito ativo na construção de seu próprio conhecimento. Torna-se importante estimular o aluno a pensar criticamente a potencialidade criadora do homem na busca de novas tecnologias para superar as distâncias do tempo e do espaço no processo de aproximação e integração entre os lugares e territórios do mundo. (BRASIL, 1998). Nessa direção, a narrativa de nosso colaborador é bastante elucidativa:

No planejamento eu posso incluir a participação dos alunos como auxiliares no desenvolvimento das atividades em sala de aula. Por exemplo, conforme te relatei anteriormente, as atividades propostas com o uso do jogo, começaram com os alunos. Inclusive, foi feito todo o percurso com o apoio dos alunos, como se fossem meus "monitores". Essa estratégia, ela foi muito bem aceita por todos os alunos que entraram na disciplina. Eles já tinham certa afinidade com o jogo, então muitas vezes eles traziam possibilidades de ensinar Geografia e Matemática dentro do jogo. Inclusive na culminância no 
final do semestre, eles montaram uma aula explicando o conteúdo de Geografia através do game. (FARIA, 2019)

É notório que uso das novas tecnologias, permite o desenvolvimento de um grande número de oportunidades e potencialidades. No entanto, fica claro também, que para alcançar êxito nas atividades propostas é necessário alguns elementos e cuidados, no intuito de envolver o aluno como sujeito ativo do processo de ensino-aprendizagem. Assim, o uso das TICs sugere uma nova lógica no modelo de aulas, planejamento, currículos e até na comunicação e organização escolar. No planejamento didático com uso das TICs, deve prevalecer uma organização aberta e flexível, principalmente ao se trabalhar com projetos a partir de experiências adquiridas. Professores, ao elaborarem um planejamento didático, devem saber que existe a necessidade de diagnosticar e selecionar o que melhor possa atender aos alunos em consonância com a realidade atual (MORAN, 2009).

Coadunando com a advertência de Moran (2009), nossos professores colaboradores fazem as seguintes ponderações sobre a importância do planejamento, no desenvolvimento das atividades com as TICs;

É necessário, primeiro conhecer os alunos, identificar o que tem na escola. Até agora já programei, no segundo trimestre, o meu plano de ensino, e aí quanto ao planejamento eu tento abordar no plano de ensino. Só que nem sempre é possível... tento colocar no Geral, e à medida que a gente vai trabalhando, e às vezes surgem necessidades ou novas idéias, às vezes até dos próprios alunos para você trabalhar determinado conteúdo. Daí a necessidade de adaptação. (FARIA, 2019).

O planejamento existe. Na prática às vezes não funciona, porque entra aquela questão da infraestrutura. No ato do planejamento o equipamento pode estar disponível e, posteriormente, na hora da prática, ter danificado. Eu sempre tento utilizar a tecnologia de acordo com o conteúdo. Para tentar inovar, a intenção é sair e não ficar muito preso aos livros, tentar trazer para o aluno a realidade atual, eles estão praticamente conectados o tempo todo, por que não conectar a disciplina?! (SANTOS, 2019).

Outro aspecto bastante evidenciado nas narrativas de nossos colaboradores se relaciona com as dificuldades impostas pela realidade de diversas escolas, que apesar de não impedir, exige dos docentes um enfrentamento desses obstáculos:

Minha realidade na escola hoje é marcada pela falta de internet ou de uma internet boa. Eu trabalho em duas escolas: em uma, a internet não é suficiente, às vezes, nem para o trabalho da secretaria. Aí, quando você abre essa internet com os alunos uma proposta defendida pelo próprio secretário Estadual de Educação: usar a wi-fi para os alunos e até o próprio Smartphone dentro da escola. Mas internets das escolas, em geral, são de baixa qualidade, muito baixo, muito baixa velocidade. Outro obstáculo se refere aos laboratórios de informática. Muitas escolas estão com os laboratórios de informáticas defasados. Então você planeja e acaba tendo que substituir, replanejar. Você 
acaba ficando com planejamento prejudicado... Isso não significa que você não queira utilizar, mas algumas vezes não dá para fazer, a gente às vezes acaba dentro da adaptação, sendo às vezes Camaleão e se adaptar. (FARIA, 2019)

Não obstante os obstáculos sinalizados depreendem-se, pelas narrativas de nossos entrevistados, que a formação e a atuação de um novo perfil de professor, que utilize a TICs como um caminho metodológico para o ensino, exige que alguns docentes tenham uma disposição para quebrar paradigmas e preconceitos enraizados em suas práticas.

Uma dica que eu dou para o professor, quando estiver planejando a aula, que procure pensar no público para o qual se destina a aula dele. Professores da minha idade, que tem 40 anos, tiveram acesso à internet depois de certa idade. Já os alunos de hoje, nascem com acesso à internet, com acesso a smartphone, acesso a várias tecnologias de informação que a gente não tinha. Então, às vezes, o professor que tem certo receio de usar essa tecnologia, até porque às vezes ele não tem muita habilidade com a mesma, não tem muita afinidade com ela, deve se superar, pois tem que entender que, embora o professor não domine, o seu aluno conhece a tecnologia e, portanto, o aluno dele necessita desse recurso. (FARIA, 2019)

Santos também ressalta:

Com certeza, aqueles professores que já trabalham 20,30 anos, passam por dificuldades em se adaptar até mesmo em sua vida. Por isso precisam se arriscar também na escola. Eles precisam botar a cara, botar para valer, não só ficar naquela coisa: não vou mexer, porque não sei. Os alunos dele hoje são de outro perfil comparado aos de 20,10 anos atrás (SANTOS, 2019).

O professor é um dos principais agentes no processo na educação. Em consequência, se torna também responsável pela melhoria da qualidade do ensino oferecido, juntamente com as outras esferas que compõem o sistema educacional. A atuação crítica e consciente do professor é imprescindível, nas mudanças que se pretende nas novas relações de ensino, com foco na aprendizagem dos alunos. Nessa direção, apontamos que alternativas como as TICs aplicadas à educação, têm como premissa dinamizar o processo de ensinar e aprender. No entanto, é consenso também, que a efetivação desse processo depende claramente de esforços e buscas pela utilização das TICs de formar adequada, para que o professor se torne um mediador e facilitador, além de estar em constante avanço em sua prática diária.

\section{Considerações finais}

As narrativas docentes e as reflexões aqui encetadas possibilitaram detectar, nas concepções dos professores colaboradores, que categorias relacionadas ao ensino de Geografia, podem ser exploradas de forma mais atraente e significativa para seus alunos, utilizando como alternativa de ensino as TICs. 
As narrativas de nossos colaboradores nos dão pistas e sinais de que saberes e práticas docentes, gestadas, adaptadas e construídas no cotidiano da sala de aula, tendo como eixo principal a utilização das novas tecnologias, apontam para a possibilidade e potencialidade do uso de TICs no ensino da Geografia.

O ensino no século XXI requer um grande esforço do professor e de todo sistema educacional para conhecer, dominar e implementar de forma eficaz os recursos tecnológicos, no intuito de garantir que os alunos tenham maior interesse pelas aulas e com isso aprendam os conteúdos curriculares necessários, de forma reflexiva.

As possibilidades de uso das Tecnologias da Informação e Comunicação no ensino da Geografia são inúmeras, mas para que as aulas se tornem diferenciadas e significativas é preciso avançar para além do domínio do aparato técnico. É necessário que todos os envolvidos tenham consciência das causas e consequências da sua utilização, e que para todo novo conhecimento adquirido, haverá novas mudanças, tanto na prática cotidiana dos docentes, como na aprendizagem por parte dos alunos.

Ao se propor integrar as TICs para uso na educação de maneira planejada, é necessário respeitar os diferentes estágios de domínio em que professores e alunos estão, podendo, assim, essas ferramentas demonstrar todo seu potencial de auxilio nas atividades propostas no ambiente escolar.

As narrativas de nossos colaboradores revelam que os mesmos têm convicção das contribuições que as novas tecnologias podem/devem propiciar ao ensino de Geografia e de sua contribuição para a formação de seus alunos, e também das potencialidades que as novas tecnologias de informação e comunicação podem trazer para a construção das identidades dos discentes no espaço escolar e também no âmbito social.

\section{Referências}

ALARCÃO, I. Professores reflexivos em uma escola reflexiva. 3ª . ed. São Paulo: Cortez, 2004. ALMEIDA, M. E. B. de. ProInfo: Informática e Formação de Professores. vol. 1. Série de Estudos Educação a Distância. Brasília: Ministério da Educação, Seed, 2000b

ANDRADE, R. B.; SACRAMENTO, A. C; SOUZA, M.S.P.S. de. Educopédia: uma forma de ensinar geografia. Anais da I Jornada Ibero-Americana de Pesquisas em Políticas Educacionais e Experiências Interdisciplinares na Educação. Brasília-DF: Grupo Nova Paideia, 2016.

BENJAMIN, W. O Narrador. In: Magia e Técnica, Arte e Política. Obras Escolhidas. Trad. Sérgio Paulo Rouanet. São Paulo: Brasiliense, 1985. P. 197-221.

BOM MEIHY, J. C. S. Manual de História Oral. São Paulo: Loyola, 1996. 
BRASIL. Base Nacional Comum Curricular (BNCC). Brasília: MEC. 2017. Disponível em: $<$ http://basenacionalcomum.mec.gov.br/images/BNCC_20dez_site.pdf. Acesso em 17 de dezembro de 2019.

BRASIL. Secretaria de Educação Fundamental. Parâmetros curriculares nacionais: geografia / Secretaria de Educação Fundamental. - Brasília : MEC/ SEF, 1998. 156 p.

CARVALHO, E. N.; VLACH, V. R. F. Vivenciando a Geografia no Ensino Fundamental: a construção da cidadania. In: IX Encontro de Prática de Ensino de Geografia: Mundo contemporâneo, práxis educativa e ensino de Geografia, 2007, Niterói-RJ. Anais... Niterói-RJ: Universidade Federal Fluminense, 2007. CD-ROM.

DELGADO, L. de A. N. História oral, memória, identidades. In: História oral, memória, tempo, identidades. Belo Horizonte: Autêntica, 2006

FARIA, S. F. Entrevista oral gravada. [set.2019]. Entrevistador: Thiago Barcelos Pereira. Cariacica- ES, 2019

HOWE, N.; STRAUSS, W. Generations. New York: Harper Perennial, 1992.

HOWE, N.; STRAUSS, W. Millennials rising, the next great generation. New York: Vintage, 2000 .

KENSKI, V. M. Sobre o conceito de memória. In: FAZENDA, Ivani (org) A pesquisa em educação e as transformações do conhecimento. Campinas: Papirus, 1997.

MORAIS, G.M.S. As tecnologias no contexto escolar: dois quadros e um desafio. Revista Tecnologia educacional, n.149, 2000. p. 38.

MORAN, J. M. A educação que desejamos: Novos desafios e como chegar lá. 4. ed. São Paulo: Papirus, 2009.

NOGUEIRA, V. Educação e cidadania na educação geográfica: os saberesdiscentes e a formação da consciência espacial-cidadã. In: IX Encontro de Prática de Ensino de Geografia: Mundo contemporâneo, práxis educativa e ensino de Geografia, 2007, Niterói-RJ. Anais... Niterói-RJ: Universidade Federal Fluminense, 2007. CD-ROM

PALFREY, J. e GASSER, U. Nascidos na era digital: entendendo a primeira geração de nativos digitais. Porto Alegre: Artmed, 2011.

PESSOA, J. D. O ensino de geografia e as tecnologias da informação ecomunicação: Uma Proposta de Formação Docente na Modalidade de Ensino à Distância. Universidade Federal do Paraná. 2011.

PRADO, M. E. B. B. O uso do computador na formação do professor: um enfoque reflexivo da prática pedagógica. Brasília-DF: MEC/PROINFO, 2008 (Coleção Informática).

SAMPAIO, M. N.; LEITE, L. S. Alfabetização tecnológica do professor. $6^{\text {a }}$.ed. Petrópolis - RJ: Vozes, 2008). Disponível em: http://www.unirevista.unisinos.br/pdf/UNIrev Vianna.pdf Acesso em 17 de dezembro de 2019.

SANTOS, F. S. Entrevista oral gravada. [set.2019]. Entrevistador: Thiago Barcelos Pereira. Cariacica- ES, 2019

SERRANO, D. P. (2011): “Geração X, Geração Y, Geração Z”, IFDBlog. Disponível em http://www.ifd.com.br/blog/marketing/geracao-X-geracao-y-geracao-z-\%E2\%80\%A6/.

Acesso em 17 de dezembro de 2019. 


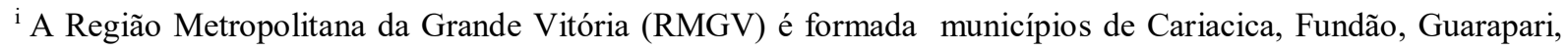
Serra, Viana, Vila Velha e Vitória. Foi constituída pela Lei Complementar estadual 58, de 21.02.1995, quando era conhecida como RMV - Região Metropolitana de Vitória e posteriormente modificada em 1999 e 2001, quando incorporou, respectivamente, os municípios de Guarapari e Fundão, passando a se chamar RMGV - Região Metropolitana da Grande Vitória.

ii Baby Boomers é a geração dos nascidos após Segunda Guerra Mundial até a metade da década de 1960. A designação vem da expressão "baby boom", que representa a explosão na taxa de natalidade nos Estados Unidos no pós-guerra. 